\title{
Einladung des BDDH e.V.
}

Im Rahmen der Jahrestagung der GTH e.V. in Berlin findet traditionsgemäß gleichzeitig das berufspolitische Symposium des BDDH e.V. statt. Dazu möchten wir alle hämostaseologischen Kollegen und Interessenten des Fachgebietes ganz herzlich einladen. Im Anschluss daran erfolgt die alljährliche Mitgliederversammlung des Berufsverbandes.

Im Namen des Vorstandes des BDDH e.V.

Dr. med. Ute Scholz

BDDH-Treffen: 27.02.2019 (Mi): 14.30-16.00 Uhr Hotel Estrel (Berlin), Saal: Europa

27.02.2019:

14.30-15.30

öffentlicher Teil:

"Ein Jahr Behandlungsvertrag"

Vorsitz: U. Scholz, G. Kappert
14.30-14.40

... Aus der Sicht des BDDH

J. Koscielny (Berlin)

14.40-14.50

... Aus der Sicht des VDEK

M. El Talia (Berlin)

14.50-15.00

... Aus der Sicht der AOK

B. Piep (Berlin)

15.00-15.10

... Aus der Sicht des Anwenders

W. Mondorf (Frankfurt/Main)

$15.10-15.30$

Diskussion

27.02.2019:

15.30-16.00

Nicht-öffentlicher Teil:

"Mitgliederversammlung"

Vorsitz: U. Scholz, J. Koscielny 